\title{
Competency-Based Approach in Training Nurses and Midwives in Morocco Demystify to Better Use
}

This article was published in the following Dove Press journal:

Advances in Medical Education and Practice

\section{Said Abouzaj}

Doctoral Studies Center of the Faculty of Medicine and Pharmacy, Mohammed $\checkmark$ University of Rabat, Rabat, Morocco
Correspondence: Said Abouzaj

Doctoral Studies Center of the Faculty of Medicine and Pharmacy, Mohammed

$\checkmark$ University of Rabat, Rabat, Morocco

Tel +2I 2666803246

Email saidabouzaj@hotmail.com
Abstract: Nowadays, the initial training of nurses and midwives in Morocco represents a turning point. Faced with the multiple actors involved in this training and the proliferation of training institutions, the quality of the offered training should decide the attractiveness of these institutions. The quality of training depends on the training approaches adopted by the institutions. In fact, an approach that promotes skills development and building and is learner-centred would add more value to the institution at the expense of traditional content and transmission-centred approaches. The purpose of this article is to present the competency-based approach in a simple way and to demystify the concept of competence in order to encourage its use in training nurses and midwives within the training institutions of the Ministry of Health that, so far, continue to operate according to the objective approach. After an attempt to demystify the definition of the concept of competence, the article highlights the characteristics of the teaching according to the competency-based approach and proposes some tools of teaching, learning and skills assessment.

Keywords: competency-based approach, training, nurses, midwives, teaching, learning, evaluation, assessment

\section{Introduction}

For years, the issue of Competency-Based Approach (CBA) for the training of nurses and midwives in Morocco has been a debatable subject among trainers and professionals at the training institutions of the Ministry of Health. The transition from the Objective Based Approach (OBA), adopted since the 1980s, to the CBA has become a necessity in order to ensure the training of competent health care professionals, who are able to answer to the strategic needs of the system and the expectations of the population.

To this end, several actions have been undertaken to prepare for this transition, ranging from the organization of training sessions for the capacity building of trainers in CBA to the development of some training modules according to the CBA, as a pilot basis for experimentation and evaluation before generalizing the approach to all training curricula. Despite all these attempts, there has been no change in the training approaches where the OBA continues to be adopted even with the implementation of the BachelorMaster-Doctorate reform in 2013 and the revision of the training programs.

In 2017, the Ministry of Health, as the supervisory department of the Higher Institutes of the Nursing Professions and Health Techniques, revised the training programme for midwives and developed a new training curriculum according to the CBA, the successful implementation of which will provide a real opportunity for the adoption and generalisation of the CBA to all training curricula. 
Thus, this article attempts to introduce the CBA and simplify it in order to help trainers and supervisors involved in the training of nurses and midwives to make use of this approach and integrate it into their daily practices.

\section{History of the Training of Nurses and Midwives in Morocco and Main Reforms of Studies}

The training of nurses and midwives in Morocco is one of the oldest vocational trainings in the country. The first nursing training schools, of the Ministry of Health, with the institutionalization of national diplomas, were opened in 1957. ${ }^{1}$ For midwives, training began as a specialization in obstetric nurses ${ }^{2}$ or midwifery nurses, and it was only in $1973^{3}$ that the midwife status saw light.

On the pedagogical level, and in order to support this training system and ensure quality training, there has been the training of specialist nurses for teaching and paramedical supervision since $1962 .{ }^{4}$ Since then, several revisions and updates have been made to the training programmes, and a lot of seminars and workshops have been regularly organised for teachers to strengthen their skills, particularly in the field of pedagogy/andragogy. ${ }^{4}$

This dynamic has reached its peak in the 1980s, when the Ministry of Health launched a major training programme for teachers in the objective-based approach, which was one of the first steps to the reform of the paramedical training system in 1993.

\section{Reform of 1993}

The 1993 reform was a historic turning point in the evolution of paramedical training, in particular, and the paramedical professions, in general, in Morocco. ${ }^{4}$ This reform was based on three guiding principles:

- The increase of the level of access to training, which has become open to holders of the baccalaureate diploma;

- The prolongation of the training period from two to three years;

- The grouping of training schools into a single training institution and the creation of the Health Careers Training Institutes in (HCTI). ${ }^{5}$ The creation of HCTI was considered as a revalorization of the training system for paramedical professionals by classifying them among the type B executive training institutions.
In addition, this reform opened the way for the first time to the privatization of paramedical training in Morocco, which was provided exclusively by training institutions of the Ministry of Health until 1993. This privatization has resulted in the creation of many training institutions by the private sector in the form of vocational training schools and institutes, or higher education faculties and institutes from 2013, after the implementation of the Bachelor-Master-Doctorate reform.

\section{Reform of 2013}

In 2013, the basic training system underwent a major reform in accordance with the Bologna Agreement, leading to the creation of the Higher Institutes of the Nursing Professions and Health Techniques (HINPHT) as higher education institutions not belonging to universities and under the supervision of the Ministry of Health. ${ }^{6}$ This reform was dictated by a lot of factors and circumstances that accelerated its implementation, combining what is strategic, as the political will of leaders, with what is professional, as the strong mobilisation of Nurses and unions.

In this reform, emphasis was placed on reorienting the academic training of paramedical staff to strengthen their level of knowledge and professional skills. This reorientation of vocational training focused primarily on reforming academic health institutions and the national educational system. This reform is also marked by the raising of the academic level of training for paramedical professionals. Indeed, it moved from initial training, marked by the award of state diplomas at the end of professional studies, to those of the university system, focused on the acquisition of the Licence, Master and Doctorate. ${ }^{7}$

The LMD reform was a strategic choice for the Ministry of Health and provoked strong expectations among students and professionals as it provides an opportunity for:

- The repositioning of the nursing training system within the national, educational, and training system;

- The financial and statutory upgrading of professionals.

- The improvement of training through the revision of the content and methods of training of professionals with the following objectives:

- Improving the quality of teaching and the content of training;

- Sharing a number of common lessons among professionals from different fields so that they acquire a common language and culture; 
- The decompartmentalization of the different study programmes by allowing the establishment of educational gateways;

o The preparation of professionals for a process of continuous improvement of their knowledge and practices by raising their awareness of research;

- The design of higher-level training courses (masters) allowing professionals to evolve towards more extensive skills in care and advanced practices;

○ The possibility for health professionals to engage, with the establishment of doctoral studies, in a career of teaching or research in care, and thereby, the development of clinical research that is currently almost non-existent.

However, while the objectives of the reform have been achieved in terms of the status and academic and administrative recognition of diplomas, the same cannot be said in terms of pedagogy and the revision of the training curricula in the various disciplines. This situation has triggered the need for a thorough reconsideration of the training approaches focusing on performance, for the reform has focused solely on the form aiming at adapting the curricula to the educational standards of higher education. Thus, the same training programs in effect previously have been renewed with the same content and learning objectives.

\section{Old Training Approaches in the Basic training of Nurses and Midwives}

Before the 1993 reform, the training programmes in place at the training schools were designed according to a biomedical approach, focusing on pathology and technicality. This approach has produced good paramedical professionals with a high level of technical skills, still they were considered as simple care providers.

In 1993, one of the objectives of the reform was to improve the quality of the training through addressing different aspects, with more focus on the pedagogical one, in order to train health professionals with an analytical and reflective mind towards their profession. At that time, and under the influence of writings such as those of Benjamin BLOOM in the field of education, in general, and Jean Jacques GUILBERT in the field of paramedical education, in particular, paramedical training in Morocco was strongly influenced by objective-based approach. To this end, it was decided to adopt this approach in the design and development of new training programmes with more focus on revised and updated content.

The adoption of this approach has been of great benefit to post-reform training, especially in its early stages, because of its simplicity of implementation, its focus on knowledge development and, above all, its rigour in evaluating learning. ${ }^{8}$ Over the years, the limitations of this approach have begun to emerge. The fragmentation of the knowledge it generates and its inability to evaluate the affective domain have led to the training of hypertechnical professionals at the expense of developed knowhow. Consequently, patient care focused on technicality and not on the human. Therefore, a reflection on a better approach to training has emerged.

Since 2002, the Ministry of Health has initiated a program to strengthen nursing skills in Morocco in collaboration with the University of Montreal in Canada, and the notion of competence and the competency-based approach has been introduced. One of the objectives of this program was to prepare nursing professionals specialized in paramedical education at the master's level, able to lead and implement this new approach.

Since then, workshops and training seminars on the competency-based approach have increased in favour of teachers, who aimed at building their capacity in competency-based teaching, with an emphasis on debates on the use of active teaching methods, and the need to focus on teaching the student. However, this dynamic has not been followed by a revision of training programmes under the CBA, even during the 2013 reform.

Currently at the HINPHT, teaching and learning is done according to the OBA which is content-centred, it aims to develop learners' knowledge in predefined areas and help them to acquire the various types of knowledge designed for this purpose. The purpose of teaching and learning is to enable learners, at the end of the course, to define, quote, describe ... without worrying about how to use and mobilise this knowledge to deal with complex professional situations.

The gateway to this approach is the learning objective, training programs are designed around a set of objectives that are presented as learning outcomes, and the expected outcome of the training curriculum is limited to the acquisition of knowledge. The teaching style most often adopted is a transmissive style that sometimes has the appearance of a constructive style. In fact, more and more teachers use student involvement by calling them to do group work and presentations, then students come 
to transmit the results of their work, which remain focused on the content and objectives to be achieved, it is quite simply a transmissive style made by the student instead of the teacher.

In 2015, the Ministry of Health undertook a revision of the midwifery training programme based on the CBA as a pilot basis, before extending the approach to all training programmes of nursing specialities at the HINPHT. Thus, and in order to ensure the correct implementation of this new programme according to the CBA, a curriculum teaching guide for teachers has been developed, focusing on the teaching and learning process through authentic professional situations.

\section{The Concept of "Competence"}

The notion of competence appeared at the beginning of the 20 th century at the company's level. At that time, the industrial revolution was at its height, and companies, guided by production and competitiveness, were looking for competent personnel able to act and manage complex and unexpected situations.

However, and depending on the work organisation adopted by the company, the concept of competence can take two forms. Thus, in a Taylorian organisation, being competent means know-how or being able to carry out a prescribed operation; And in an open organisation, being competent means being able to act more, that means being able to manage complex professional situations, deal with events and take initiatives, etc. Competence is no longer limited to executing instructions or applying procedures.

As a result, and for economic reasons related to the labour market, vocational training schemes have been obliged to integrate this concept into their training programmes, meeting the needs of companies as employers' organisations. So, these vocational training systems are starting to build up business references based on the analysis of skills used in professional situations, and skills are becoming instrumentalized and referenced and measured according to the market economy. ${ }^{9}$

In the 1980s, the emergence of the competency concept and the development of the competency-based approach arrived at schools and universities in response to the concern to solve the problems and limits identified with the objectivebased approach. ${ }^{8}$ Since then, there have been many attempts to define this concept in order to simplify and contextualize it.

Several definitions of the concept of competence exist in the literature. After a broad domination of the objectivebased approach in the field of education and training, which is known by its focus on content and knowledge, the first definitions of competence were built around knowledge as resources, thus marking a transition phase from knowledgecentred teaching and learning to results-centred teaching and learning. Later, a new concept appeared in the definitions of competence referring to the way in which knowledge was used or processes, to finally reach definitions linking competence to performance. The analysis of these different definitions reveals three categories of definitions that appeared according to the following chronology: a) resource competence, b) process competence and c) performance competence.

\section{The Concept of "Resource Competence"}

One of the authors who defined competence independently of the result is Naom Chomsky. ${ }^{10}$ For this author, we can be competent simply by having knowledge even without a corresponding performance. Competence is only one ingredient, necessary but not sufficient, of performance. But this notion of competence was quickly overtaken by its very limited scope of application to language activity, and consequently its non-transferability to other disciplinary fields.

In 1984, Maurice de Montmollin ${ }^{11}$ proposed a definition of competence based essentially on knowledge, without clearly stating how it should be used or how it relates to the desired result. So, he defines competence as a stabilized set of knowledge and know-how, standard behaviours, standard procedures, types of reasoning, which can be implemented without new learning. The notion of competence is still marked by the influence of the cognitive approach and the domination of cognitive processes in learning.

\section{The Concept of "Process Competence"}

Since the 1990s, several definitions of the concept of competence have emerged with new elements, focusing on how to use the resources acquired to deal with problematic situations. Thus, in 1994 Le Boter ${ }^{11}$ defined competence as a know how to mobilise that does not reside in resources but in the mobilisation of these resources. So, competence is not a state, it is a process. This definition was strongly supported by Tardif in 1999, ${ }^{11}$ who presents competence as a complex know-how based on the mobilisation and effective combination of a variety of internal and external resources within a family of situations. It was also maintained by Rogier in $2000^{11}$ who presents competence as the possibility for an individual to internally mobilise an integrated set of resources to solve a family of problem situations. 
According to these definitions, being competent is not only limited to the possession of knowledge and the knowledge acquisition. Rather, the competence lies in the process adopted to mobilise the right available resources and their use in the best way to solve a given problematic situation. To this end, the CBA teaching should enable the learner to take constructive action in order to implement all the acquired knowledge and skills through well-defined processes as to achieve a specific result.

\section{The Concept of "Performance Competence"}

After defining the concept of competence through the resources and the process of their use, the definitions could not answer the question of competence assessment. As this is not observable and measurable, it was necessary to introduce a new element that would make it possible to evaluate competence. Thus, performance appears as an expression of competencies. This is because the development of skills by learners is strongly linked to the contexts in which they are implemented. Consequently, at the time of learning, the learner is called to apply his various acquired knowledge, which presupposes that he enters into action through the implementation of integration activities that reflect performance.

During the 1990s and 2000s, definitions of the concept of competencies began to link knowledge and processes to performance. Thus, the notion of performance has been translated in different ways, in the form of problem solving and project implementation (Mark DEROMINVILLE, $1998^{12}$ ), in the form of identifying a problem task and solving it through effective action (Pierre GILLET, 1991 ${ }^{13}$ and Jacques TARDIF, $1996,{ }^{11}$ or in the form of purpose and goal (Bernard REY, $2009^{11}$ for whom talking about skills entails talking about acts that have a purpose.

It appears from all these definitions that the concept of competence is a dynamic concept whose definition has been constructed over time, according to contexts and with reference to different schools of thought. But, all definitions agree that being competent requires three things:

- To have knowledge and know-how as mobilisable resources. We cannot be competent without the knowledge that underlies our actions, otherwise we would be executors;

- To have the ability and capacity to mobilise the right resources available (internal resources) and be able to combine them with other resources (external resources) and know how to use them in different situations. In other words, it is the putting into action and in action of the different resources;

- To be efficient which means to achieve the expected result. The resources held and their mobilisation and use must converge towards the goal to be achieved or the desired performance, which is the key element and the purpose of the competence. The possession and use of knowledge must respond to a given problematic situation and to provide the answer and solution.

As a result, competence is considered as a real system that functions from inputs (knowledge and know how) used in action according to a process (knowledge mobilisation) to achieve outputs or results (performance).

\section{Teaching According to the CBA To Teach According to the CBA}

Competence includes three essential elements: the knowledge and skills to be developed as resources, how to use and mobilise this knowledge as a process and the desired performance as results. Unlike the OBA, whose teaching and learning is limited to the development and acquisition of knowledge, the CBA is an approach in which teaching and learning focus much more on the process, which means how to act or how to use and mobilise resources to achieve the desired result. Therefore, teachers should revisit their practices by focusing on process and performance and consider the development of knowledge only the first step.

Teaching according to the CBA involves the preliminary definition of performance in terms of desired outcomes, and all the process must accompany the student towards achieving that outcome. The performances are defined in terms of capacities in the training curriculum; they are observable behaviours that each student must develop at the end of the training and which reflect the different professional activities required to practice the profession.

The tenet of teaching according to the CBA is the professional situation or clinical case, which must be as close as possible to the reality's context, and according to the capacity to be developed so that the learner develops effective skills. The professional situation is the main teaching and learning tool, it is used to teach, learn and evaluate at the same time. According to Léopold et al, ${ }^{14}$ the situations proposed to learners require the integration 
of diverse skills, there must be a common thread in everything proposed, with a complex and articulated set of tasks to be done, which are oriented in a precise direction, and not series of small questions unrelated to each other.

The teaching approach according to the CBA is as follows (Table 1):

- Preliminary step:

o Present the competency and the corresponding module; the module must be presented in terms of the capacities to be developed and not in terms of objectives to be achieved (at the end of the module, the student must be able in terms of "capacities" rather than "objectives").

- Define the desired performance or result (capacities).

- Present the professional situation or clinical case that is built around the performance to be developed (depending on the teacher's choice, the professional situation may be built around a single capacity or a simple situation, or around several capacities or complex situations).

o Collect students' responses and guide them to identify the knowledge needed to achieve the desired performance (the knowledge needed to resolve the professional situation identified by students may be from different disciplines).
- Determine the list of knowledge related to the desired performance and send the other knowledge to the other modules.

- 1st step: Development of identified knowledge or knowledge teaching:

This is the first step in the development of competence; it is about the resources needed to achieve the learning outcomes. At this stage, the objective is to ensure that students have acquired the necessary knowledge. The teacher can use different teaching methods that best guarantee the acquisition of the identified knowledge (interactive presentation, group work, exercises, reading, etc.).

- 2nd step: use of knowledge or teaching the process:

This is the step often omitted in the OBA. Because it is not enough to teach students knowledge, they must be taught how to use it to solve a professional situation. Hence, knowledge is not the end, it is the resource. The principle is to show students how to mobilise the right resources and combine them to deal with the problem. This is the most crucial step that would make the difference between a student who has knowledge but does

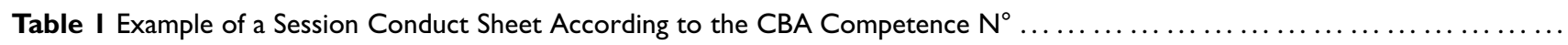

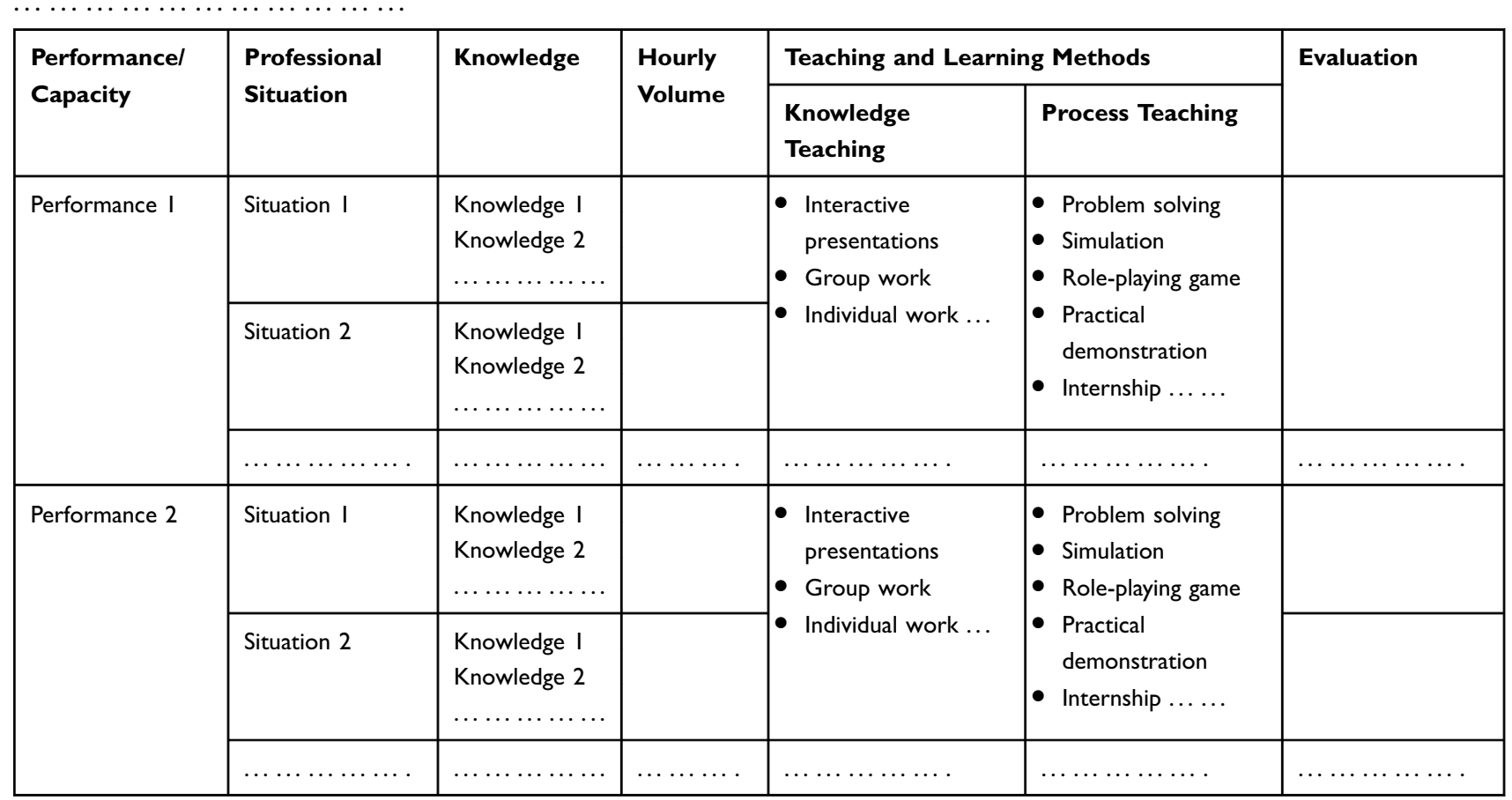


not know how to act and a student who has knowledge and knows how to act.

Depending on the capacity to develop, the teacher uses pedagogical strategies and teaching and learning methods based on reflection and analysis, that promote learning in interaction with peers, groups or the teacher and with the learning object presented in authentic situations and contexts. These methods can be theoretical such as problem solving or problem-based learning, simulated such as roleplaying and practical demonstrations, or practical in authentic situations such as internships and tutoring. Thus, the purpose of these pedagogical strategies is to enable the learner to control, manage and self-regulate his learning process.

\section{Teaching and Learning Styles}

The constructivist and socio-constructivist style of Piaget (1896-1980) and Vygotsky (1896-1934) remains most often privileged in the CBA. It involves a coconstruction of knowledge between the teacher and students and between the students themselves and their environment. The active involvement of students in the resolution of professional and problematic situations will lead them into a dynamic, reflective and analytical process, either in interaction with the teacher or with each other, in the search for solutions by identifying and mobilising relevant knowledge and skills.

The learning styles adopted in this case will be diverse but especially all active, which avoids the posture of passive and receptive students. According to Piaget (1968), when faced with a new problem, a person will try to solve it using the intellectual tools at his disposal. The main idea associated with this vision of teaching and learning is that of the learner as a master of his own learning, who builds his own knowledge in contact with the environment and in interaction with others. ${ }^{15}$ Thus, the role of the teacher is no longer perceived as before, for he is not the only one who has the knowledge, his role is to facilitate, accompany and guide instead of transmitting.

\section{Evaluate According to the CBA}

Assessing competence simply means assessing what the learner will be able to do in the future in a professional situation. However, the evaluation of learning according to the CBA is not a simple and easy task. The principle of teaching and learning according to the CBA is based on a construction of knowledge through professional situations in which the learner learns in action. The aim is to develop skills through the acquisition of related and necessary knowledge. As a result, evaluation is considered as an integral part of the process and covers the different stages of its implementation.

Indeed, the evaluation of learning according to the CBA has been approached in different ways, while having the same purpose namely the degree of development of the competence. The integrative and combinatorial nature of a competence is opposed to the fact that the different areas of knowledge are assessed separately, ${ }^{8}$ the evaluation must focus much more on how the learner uses and mobilises the acquired knowledge. This is only possible through the learner's confrontation with complex professional situations, called authentic situations, integrating knowledge, know-how and interpersonal skills and the way they are used to achieve a desired performance.

The "authentic" assessment perspective introduced by Wiggins $1989,{ }^{16}$ is intended to promote complex assessment situations that simulate the activities that the student will undertake in his professional life. This perspective aims to contextualize the assessment in a similar way to the contextualization of teaching/learning activities.

Competency assessment must be integrated into the teaching/learning process, and is no longer considered as a separate activity with the sole objective of final sanction. Therefore, the success of the competency assessment depends on how the competency was taught and how the student learned it. The conditions for assessing competence must be similar to those of its development during teaching/learning activities, and an authentic assessment situation must have, with some differences, the same general characteristics as an authentic teaching/learning situation. Tardif $1996,{ }^{17}$ precise, that the only way to evaluate students wisely, is to place skills in a context characterized by the authenticity of situations as in teaching.

Wiggins $1998,{ }^{18}$ summarized the characteristics of an authentic assessment as follows:

- The assessment task and situation must be realistic;

- The assessment context must replicate the same context of the student's future workplace;

- Assessment requires the student's judgment and creativity;

- The student must independently perform the tasks leading to the resolution of a problem situation; 
- The assessment must consider the student's ability to use his knowledge effectively to solve the problem situation;

- The assessment process must allow sufficient time and multiple opportunities for practice so that the student can consult the necessary resources and receive feedback in order to progress.

Authentic situation evaluation is therefore based on the measurement of complex performance. This is based on the student's ability to implement, in various situations and contexts, the cognitive and metacognitive strategies necessary to perform a task or set of tasks, ${ }^{17}$ and the teacher must then judge the mobilization of all the knowledge integrated by the student in order to perform an action.

According to Leroux J.L ${ }^{17}$ the implementation of the competency assessment must answer the following questions:

- What approach should be taken?

- What instruments should be used?

- How do we make a judgment?

- How will we arrive at a decision to validate the competence?

\section{Evaluation Approach and Instrument}

The pyramid model developed by Miller $1990,{ }^{19}$ used in medical training, provides an easy and simplistic framework for assessing competence, and could provide answers to the above questions.

The model is presented as a pyramid with four levels of competency construction, with types of assessment that are particularly adapted to each level.

The base of the pyramid corresponds to the student's knowledge, the second level corresponds to the way in which the student can use his knowledge, intellectually, or know how to perform a task, the third level corresponds to the demonstration of how the student uses the knowledge, in a simulated context, to solve a task or shows how, and the fourth level corresponds to the performance, in a real context, of the task or does.

In parallel with the teaching stages for the development of competences (resources, processes, performance), the evaluation must cover the learning made during these stages, namely the evaluation of the acquisition of knowledge required as resources (level 1), the evaluation of the process of their use (level 2 and 3), and the evaluation of performance (level 4). Competence is not observable, so its evaluation is based on the evaluation of observable behaviours, translated in this case into performances defined on the basis of capacities, which are themselves declined from competence.

Based on Miller's pyramid, the competency assessment process can follow the path of the four levels of the pyramid without fragmentation of levels; the assessment must take place at the same time and requires preparation in advance, and will be done using the tools designed for this purpose.

- Knowledge assessment: as already mentioned above, knowledge of different types is the essential resource for skills development, and we cannot claim to be competent without knowledge. Therefore, this knowledge must be evaluated in order to verify if the student has been able to acquire the different knowledge that underlies the competency. The evaluation tools used at this level can be so-called classical tools such as multiple choice questionnaire, essay questions, open and short answer questions, etc.

- Assessment of how the student can use his knowledge, intellectually, to perform a task or know how: the possession of knowledge alone cannot guarantee effectiveness in solving complex tasks. As a result, the student is applied to demonstrate the ability to mobilize resources relevant to the situation to be resolved. This knowledge mobilisation can be developed with the students through case studies, problem analysis exercises, etc.

- Assessment of how the student can use his knowledge, in a simulated context, to solve a task or shows how: during this stage, the student must demonstrate, through role-playing and/or simulations, his ability to apply his knowledge, whose use or know how have already been mentally developed. This will allow the student to correct any errors before proceeding to implementation in the real context.

- Assessment of the achievement of the task in a real context or does: this is the final step in evaluating the student's performance in order to validate his competence. The student is put in a real situation in his future workplace, where he is called upon, based on his accumulated knowledge during the first three stages, to carry out a complex task by mobilizing the relevant and necessary knowledge and avoiding possible errors made previously in the simulated situation.

\section{Judging and Scoring Criteria}

When assessing student competence, the development of the measurement tool is a fundamental step. It is important 
to keep in mind all the tools that will be used to confirm that the students being assessed are capable of doing what is expected of them. The tools vary according to the level of assessment according to Miller's pyramid, these are:

- Essay questions, multiple choice questions, open and short answer questions ... for knowledge assessment;

- Analysis exercises, case studies, problem cases ... for the evaluation of knowledge use on an intellectual plane or know how;

- Role plays, simulations, practical demonstrations ... for the evaluation of knowledge use on an simulated plane or shows how;

- Real-life practices (internship) for the evaluation of the achievement of the task or does.

However, in order to be able to verify if the student has performed as expected, and to make a decision of success or failure, each tool or instrument must include judgment criteria and performance indicators, from which the decision of success or failure can be made.

The evaluation of each performance must be subject to criteria and indicators, which must be written in a clear and explicit manner in order to ensure the objectivity and transparency of the evaluation. The aim is to define quality criteria in the form of expected performance characteristics, and to clarify their indicators, which means the observable elements or aspects of performance. ${ }^{20}$

The definition of these criteria and indicators will allow the learner to direct his efforts to improve his performance, and also allow the teacher to verify the learner's success or failure (success criterion), or even to assess and precise the learner's level of performance beyond the success threshold (performance criterion). Thus, the validation of performance will depend on the degree of mastery of the criteria.

- For levels 1 (knows) and 2 (knows how), criteria can be defined such as obtaining $\mathrm{x}$ correct answers on all questions, obtaining a score at least equal to $\mathrm{x} / 20$, presenting the keywords searched for, the logical sequence of ideas during analysis exercises, etc.

- For levels 3 (shows how) and 4 (does), observation using the criterated grids remains the main tool used. The grid must include logical criteria in relation with the task requested, and each criterion must be divided into performance indicators to validate its achievement or not. For these levels, which correspond to the evaluation of performance, we can use De Ketele 2/3 rule $^{21}$ which makes possible to decide on the validation of performance and consequently the mastery of competence, it is a question of giving the learner three opportunities to check each criterion, and success is attributed if the learner succeeds at least two times out of three.

The following process proposes a competency assessment approach in accordance with the Miller pyramid, which is as follows:

- Present the competency to be assessed;

- Select the performance or performances to be evaluated, which must be defined in terms of observable behaviour and directly derived from the capacities. It is sometimes difficult to evaluate all performances, in which case it is preferable to evaluate the performances that have the highest frequency of solicitation in the professional environment;

- Present the clinical situation according to the performance(s) to be evaluated

- Step 1: Assessment of levels 1 and 2 (knows and knows how). This assessment can be done at the same time, by proposing a written exam that includes questions from different levels of analysis on the clinical situation, to ensure that the student has acquired the necessary knowledge and knows how to use it to solve the situation.

- Step 2: Assessment of level 3 (shows how). This is done by using, depending on the clinical situation and performance to be assessed, either role-playing, simulations or practical demonstrations.

- Step 3: Assessment of level 4 (does). This is done by placing the student in a real environment, and asking him to solve the clinical situation, through a series of activities and tasks to be performed. The decision to succeed or fail is made after verification that the predefined performance criteria have been met.

The four levels of assessment must be done through the same clinical situation, in order to ensure that the assessment is coherent and integrative.

Example

The competency to Evaluate: communicate effectively while exercising one's duties.

Performance to be assessed:

- Ensure the reception of the patient and his family 
- Managing conflicts

- Write a written report

Presentation of the clinical situation:

You are on duty in a hospital emergency room, when you receive a heart attack patient accompanied by his parents, wife, and children. They all seem worried, the wife and children are crying, the parents are screaming aloud in search of the doctor on duty, while accusing his wife of being the cause of the heart attack. They claim that their sons with heart disease had this seizure after he had entered in conflict with his wife.

After the on-call doctor arrives, the victim's family refuses to leave the care room and continues to exchange charges. The doctor asks you to calm the family and write a detailed report, what is your conduct?

Evaluation process (Table 2):

Step 1: Assessment of knowledge and how to use it (knows and knows how).

In this step, the student is asked to answer a series of questions about the knowledge necessary to solve the situation, such as the communication process, forms of communication, conflict management techniques, etc. He must also describe in theory how he should behave face of this situation in order to judge his analytical ability and how he mobilizes and uses his knowledge to resolve the situation.

Step 2: Evaluation of how the student uses his knowledge through demonstration in a simulated environment (shows how).

In this step, and through a role-play simulating the clinical situation, the student is asked to apply his approach, already described in the previous step, to solve the situation. In this way, it will be able to check its effectiveness and correct any errors.

Step 3: Evaluation of how the student uses his knowledge in a real environment (does).

In this step, the student is placed in a real healthcare environment, where he is called upon to carry out activities and tasks related to the assessed performance. In case if it is difficult to encounter exactly the same clinical situation in a real environment, given the nature of the competency being assessed, it will be possible to proceed by performance separately, since the evaluation criteria and performance indicators remain identical.

However, performance evaluation must not be at the expense of the global and integrative nature of the competency, it must be done while converging towards integrative competency evaluation, which remains the main focus of the evaluation.

Objectively speaking, the evaluation of each performance must be done based on the sought competence, so that after the evaluation of all the desired performances of the competence, we can have an idea of the degree of mastery of the competence by the learner.

The following table presents some performance criteria and indicators in relation to the evaluation of levels 3 and 4 (steps 2 and 3 ).

\section{Conclusion}

In a changing and competitive training environment, the adoption of the CBA in the training of nurses and midwives is a real opportunity to improve the capacities of the awardees in order to prepare them to fully accomplish their professional roles.

Teaching according to the CBA is not as complex and complicated as it seems. Certainly, it requires effort, innovation and creativity, as well as coaching and participation in order to succeed, and these are traditionally referred to as the roles of a successful teacher.

Teachers are invited to revisit their teaching and supervision practices through the analysis of the CBA and its implementation tools, as well as the right assimilation and integration of the concept of competence, which remains the key element for the success of the approach.

Table 2 Criteria and Performance Indicators for the Assessment of Communication Competence

\begin{tabular}{|l|l|l|}
\hline Performances to Evaluate & Criteria & Indicators \\
\hline $\begin{array}{l}\text { Ensure the reception of the } \\
\text { patient and his family }\end{array}$ & $\begin{array}{l}\text { Contact with the family (language used, tone, gestures) } \\
\text { Active listening ... . }\end{array}$ & Family calmed and reassured \\
\hline Managing conflict & Impartiality, mediation, equity in intervention & Relieved tension between family members \\
\hline Write a written report & $\begin{array}{l}\text { Form of the report: readability, paragraph spacing, spelling .... } \\
\text { Background of the report: relevance of information, sequence of } \\
\text { ideas, coherence of facts .... }\end{array}$ & $\begin{array}{l}\text { Readable, ventilated and clean report } \\
\text { Consible and valid report }\end{array}$ \\
\hline
\end{tabular}


A good understanding and assimilation of this concept will make it possible to properly write the training skills and the various elements that result from them (capacities and knowledge). The development of a competence, through teaching and learning activities, is the result of the combination of three essential elements and ingredients: knowledge as resources, how it is used as a process and the desired result manifested through performance.

A well-written competency with these three elements will certainly facilitate its teaching and assessment and achieve its purpose; it will also provide the framework for all future teaching, learning and assessment activities.

\section{Acknowledgements}

I would like to thank my thesis Director Pr. BARKAT Amina, Professor of Higher Education at the Faculty of Medicine and Pharmacy of Rabat - Morocco, for his valuable and high quality support and constructive comments throughout the preparation of this article.

\section{Disclosure}

The author reports no conflicts of interest in this work.

\section{References}

1. Ministère de la Santé - Maroc. Arrêté_brevet-infirmier_1.pdf. Maroc; 1957:1510.

2. Ministère de la Santé - Maroc. Arrête_spécialisation_IDE_2.pdf. Maroc; 1963:238.

3. Ministère de la Santé - Maroc. Décret_Ecoles des cadres_3.pdf. Maroc; 1973:2062.

4. Ahmed A Histoire de la formation paramédicale au Maroc. 2016

5. Ministère de la Santé - Maroc. Décret_IFCS_P780_5.pdf. Maroc; 1993. p. 780.
6. Ministère de la Santé - Maroc. Décret-Création ISPITS 6.pdf. Maroc; 2013:6507.

7. Ndecki PP. Accréditation institutionnelle. Présence Africaine. 1962; XLII(3):147.

8. Nguyen D-Q, Blais J-G. Approche par objectifs ou approche par compétences? Repères conceptuels et implications pour les activités d'enseignement, d'apprentissage et d'évaluation au cours de la formation clinique. Pédagogie Médicale. 2007;8(4):232-251.

9. Stercq PC Compétences et approche par compétences. 25-32.

10. Alain K. Competence, its definitions, its challenges. Journal Gestion. 2000;(2):31-47.

11. Roos S L'approche par compétence.

12. Frenay M, Noel B, Parmentier PP, Romainville M. L'étudiantApprenant. Grilles De Lecture Pour L'enseignant Universitaire. Boeck University; 1998.

13. Pierre G, Donnay Jean ZD, Évelyne C. Comprendre des situations de formation. Formation de formateurs à 1 ' analyse. (Coll. Pédagogies en développement, Nouvelles pratiques de formation .) enseignants et les formateurs. (Coll. Pédagogies). 1990;2018:170-174.

14. Paquay L, Carlier G, Collès L, Huyen A-M. L'évaluation des compétences chez l'apprenant. 2000:160.

15. Brahimi C, Farley C, Joubert P. L'approche par compétences Un levier de changement des pratiques en santé publique au Québec. 2011:110.

16. Dolz J, Ollagnier E, Allal L. Acquisition et évaluation des compétences en situation scolaire. L'énigme La Compétence En Éducation. 2002;75.

17. Leroux JL, Bigras $\mathrm{N}$ L'évaluation des compétences: une réalité accessible dans nos collèges [Internet]. Cégep de Saint-Hyacinthe. 2003. 176 Available from: https://www.usherbrooke.ca/performa/ fileadmin/sites/performa/documents/Recherches_subventionnees/ Leroux et Bigras 2003 .pdf.

18. Joly L Conception d'un examen clinique objectif structuré pour le volet pratique de l'épreuve synthèse du programme Technologie de radio-oncologie. 2013

19. Vleuten DEHT, van der CPM. Assessment of Professional Competence [Internet]. Media. 2014. 183 p. Available from: http://link.springer.com/ 10.1007/978-94-017-8902-8. Accessed November 28, 2019.

20. Van Nieuwenhoven C, Ricker ME. Quels critères et quels indicateurs pour évaluer les compétences des élèves? J Chem Inf Model. 2013;53 (9):1689-1699. doi:10.1021/ci400128m

21. Gerard F-M. L'évaluation Des Compétences À Travers des Situations Complexes. Actes du Colloque de l'Admee-Europe, IUFM ChampagneArdenne, Reims, 24-26 Octobre 2005, FMG ㄷ 2005. 2010:1-8.
Advances in Medical Education and Practice

\section{Publish your work in this journal}

Advances in Medical Education and Practice is an international, peerreviewed, open access journal that aims to present and publish research on Medical Education covering medical, dental, nursing and allied health care professional education. The journal covers undergraduate education, postgraduate training and continuing medical education including emerging trends and innovative models linking education, research, and health care services. The manuscript management system is completely online and includes a very quick and fair peer-review system. Visit http://www.dovepress.com/testimonials.php to read real quotes from published authors. 